\title{
3D scanning technology application in the imperfect cultural relic
}

\begin{abstract}
Data extraction of cultural relic is helpful for their records and protection. During field excavations, some vulnerable and dilapidated cultural relics may be more seriously damaged by manual drawing and measuring. Meanwhile, records of the two-dimensional data and graphic image cannot accurately reflect the situation of the unearthed relics. At the same time, due to the irregular shape of the imperfect cultural relics, the precision of the measurement can hardly meet the requirement by traditional artificial method. In this article, taking Yanxiadu deer vein residue brick during the warring states period as an example, the usage of the 3D handheld scanner has been introduced, in order to record three-dimensional data of residue brick accurately. The three-dimensional model of residual brick was measured and analyzed by $3 \mathrm{D}$ software, which provides a new way for protecting the imperfect cultural relics.
\end{abstract}

Keywords: the imperfect cultural relics, portrait brick, 3d scanning, 3d software
Volume 5 Issue 2 - 2020

\author{
Jin Wang \\ Institute for history of science and technology, Shanxi University, \\ China
}

Correspondence: Jin Wang, Institute for history of science and technology, Shanxi University, Taiyuan 030006, P R China, Email wjustb@।63.com

Received: April 03, 2020 | Published: April 13, 2020

\section{Introduction}

Portrait brick, including hollow brick and solid brick, is a brick with surface printing and mainly uses in construction and tomb chamber decoration. Began in the warring states period, portrait brick had close contact with the social history's special background. Portrait brick becomes one of Chinese art history milestones, not only because of its lofty artistic value, but also because of the precious historical data value that it displays. ${ }^{1}$ To analyses portrait brick is both to inspect its cultural value and to trail and discover the culture development of the warring states Dynasty. Under the influence of time and environment, some portrait bricks were imperfect when they were unearthed. Due to the irregular shape of the imperfect portrait bricks, the traditional artificial method cannot meet the precision requirement of measurement. A new method of high-resolution surveying and mapping provided by 3D scanning technology has been used in cultural heritage research, ${ }^{2}$ for example, in cave temples, ${ }^{3}$ rock painting ${ }^{4}$ and ancient buildings. ${ }^{5}$ Taking Yanxiadu deer vein residue brick during the warring states period as an example, we introduced how to use the 3D handheld scanner to record three-dimensional data of residue brick accurately. The three-dimensional model of residual brick was measured and analyzed by reverse engineering software, which provides a new way for protecting the damaged cultural relics.

\section{A brief introduction to the material and equipment}

\section{Material}

The yanxiadu deer vein residue brick is unearthed at Yixian xiadu site in Hebei province, which belongs to the warring states period (475-221BC). The residual brick is about $17 \mathrm{~cm}$ long, $12 \mathrm{~cm}$ wide and $5 \mathrm{~cm}$ thick and is made by ceramic. The decorative pattern of the brick is clearly visible but only half of which is remained when unearthed (Figure 1).

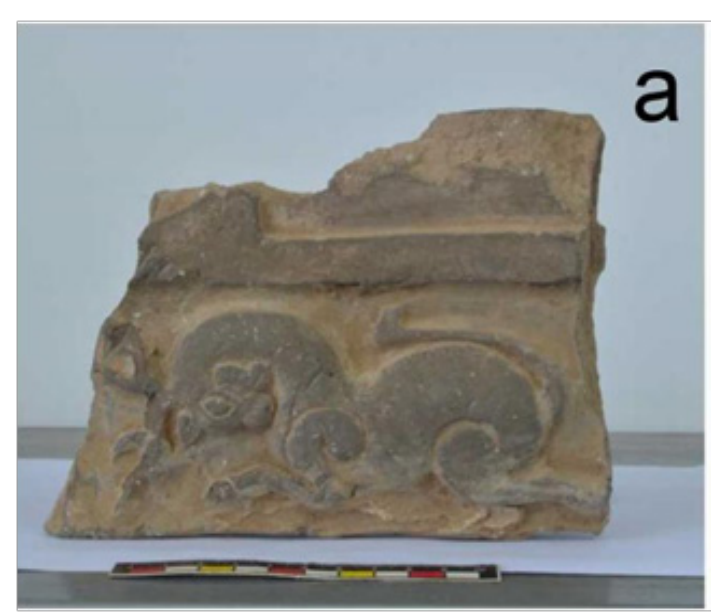

Figure I (a) The A side of the residue brick.

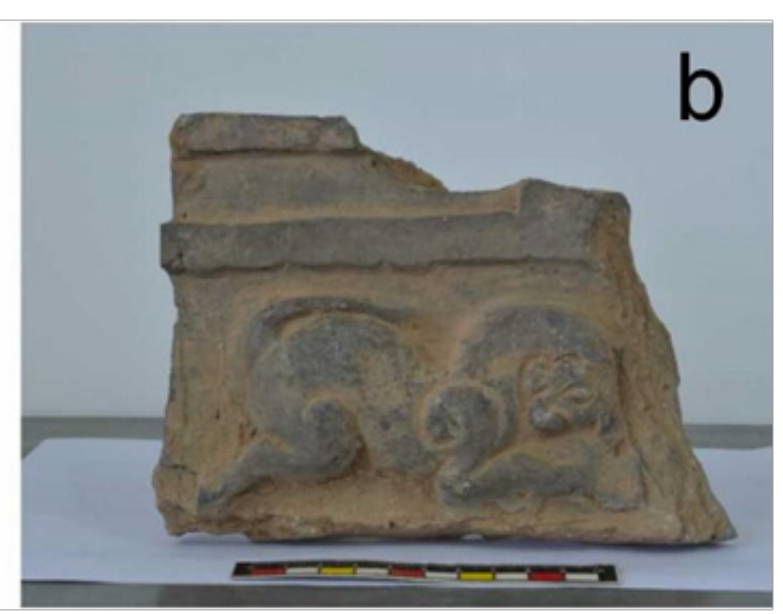

(b) The B side of the residue brick. 


\section{Equipment}

Based on the size and the damage level of the residual brick, we selected Creaform Go!SCAN 20 scanner which can achieve the geometrical and texture information from the environment. Compared with 3D laser scanner, this scanner is white light scanner with LED light source and fast scanning speed. And it is more suitable for small cultural relic. Prior to scanning, objects texture information can be added. Thus, this scanner doesn't need to texture mapping after scanning. Having $0.1 \mathrm{~mm}$ Scanning accuracy and $0.2 \mathrm{~mm}$ resolution, it satisfies the requirement of scanning.

\section{The process of three-dimensional scanning}

When using the hand-held scanner, the object is fixed so that the scanner can scan around it. Because of the uneven damage of the residual brick and the fact that both sides have deer vein, we put the residual brick in a rotating tray and scanned both sides. This can guarantee comprehensiveness of the residual brick's data and improve the working efficiency of the scanner. The whole scanning process is as follows:

(1) Set the parameters. In the Vxelements software, choose the configuration parameter for the residual brick. According to the needs of cultural relics, use "natural features" and set the resolution to 0.80 $\mathrm{mm}$ in "scan" term. Set the texture application, contrast, projection parameters and related parameters.

(2) Record the data. During the scanning, we can click on the "stop scanning" to view the model at any time. Meanwhile, the data will still be automatically processed. Because the cultural relics were in the tray, the plane of tray was also recorded into the final data when the cultural relics are scanned. The tray will be deleted if the tray is set as "tangent plane". Next, keep the 3D data of the residual brick and delete the excess noise points by using "edit plane". The data format is then retained according to the requirement of the reverse software.

(3) Get the model. Because both sides of the residual brick have deer vein, we scanned both sides in order to achieve the data integrity. Use the "merge scan" function and form a complete 3D model of the residual brick (Figure 2). Set the scanning device to "flashing" in the process of scanning, thus the $3 \mathrm{D}$ model of the residual brick is brighter than the original color. It can restore the original color by later debugging.

(4) Set the coordinate system. The residue brick should be adjusted in three-dimensional coordinates, which makes it convenient for surveying and analyzing in future. Take the 3D model into the 3D Builder in Windows 10 OS. Set rotation degrees and adjust the distances. Use "setting" function to make sure object central axis overlaps with system central axis (Figure 2).

\section{Software analysis and discussion}

The 3D model of the residual brick was imported into Geomagic Studio to accurate measurements and correct analysis. Under the threedimensional coordinate system, the residual brick was accurately measured with $173.14 \mathrm{~mm}$ long, $128.16 \mathrm{~mm}$ wide, $45.18 \mathrm{~mm}$ average thickness and $51.53 \mathrm{~mm}$ maximum thickness. And its volume is 484481.75 cubic millimeter. Bricks were mainly used in architecture in ancient times. According to Technological encyclopedia written by Song Yingxing (1600-1660) in 1637, the ancient method of making bricks is as follows: the cattle are used to trample mud which has been watered. The mold of wood is filled by sticky mud; the surface of a wood mold is scraped with a bow of iron wire. The mud is turned into bricks through the mold of wood. So far, the earliest bricks were found at the site of Houma in Shanxi Province which belongs to the spring and autumn period (770 BC - 476BC), but the quantity is small. These bricks are rectangular and square which are unornamented. In the warring states period ( $475 \mathrm{BC}-221 \mathrm{BC})$, the style of the brick is gradually increasing. The brick relief's surface is printed with the graph, including hollow brick and solid brick. This kind of brick mainly uses in construction and tomb chamber decoration. In the Western Han Dynasty (202 BC - 8 AD), the walls, gates, bucket arches and tablets in the ruler's tombs and the walls in their ancestral halls were all constructed with these bricks. On the production techniques, most of portrait bricks were molded. Meanwhile, some of which were also made from lithography. Brick relief of solid brick is molding, one-timely molded. The method of making the brick relief is as follows: place bricks and mortar in a mold and then pat it; turn and demould; burned it to bricks. Therefore, the portrait of a solid brick is decided by the mould. ${ }^{6}$

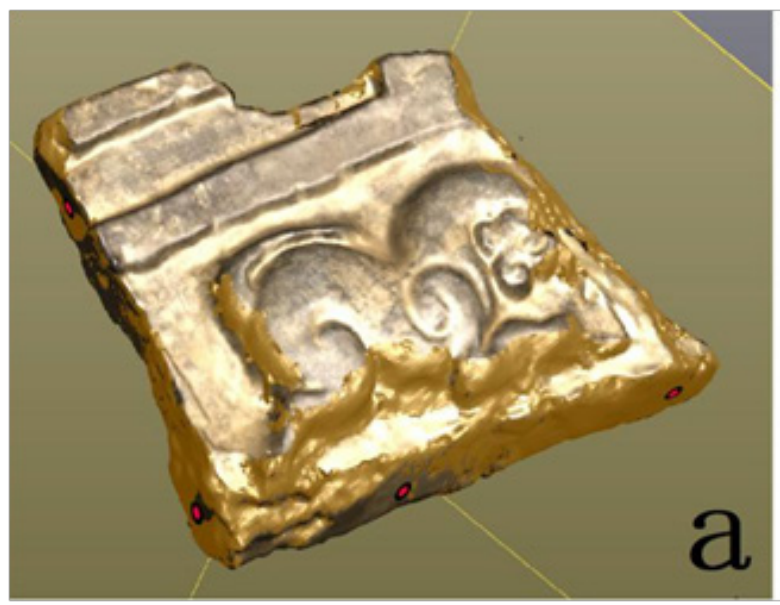

Figure 2 (a) 3D model of the residual brick.

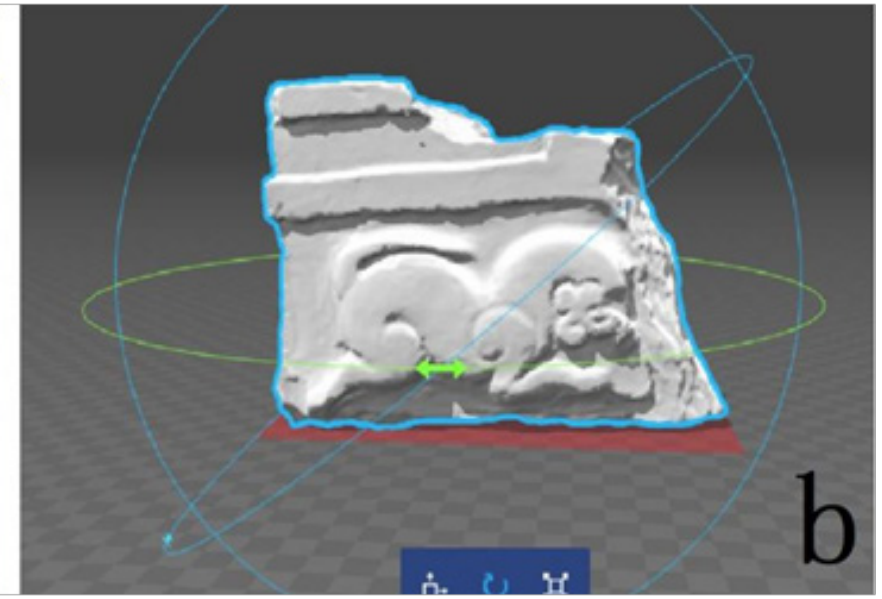

(b) Set the coordinate system. 
For the yanxiadu deer vein residue brick during the warring states period (475 BC - $221 \mathrm{BC})$, both sides of which have deer and style in a very similar form. Due to the situation on both sides of the wear and tear, we cannot judge whether both sides of the shape are made by the same mould. We can observe the changes of portrait by comparing the two sides. We set the horizontal section according to the horizontal center position of the residual brick. The horizontal section is set at the same distance to either side of the brick. The distance of longitudinal translation is $2 \mathrm{~mm}$. And the horizontal section starts from the center position and extends to both sides respectively. These changes are shown in Figures $3 \& 4$.

According to the changes of the images, the A side deer vein of the residue brick is smooth, with fast lines and meticulous carving; the B side deer vein is fruity, strong and more robust. The abrasion of A side starts from the all sides of deer vein to the center gradually; which of B side starts from the head to the haunch of deer vein. The moulds of
$\mathrm{A}$ and $\mathrm{B}$ sides are different, and the abrasions are also different. The repair plan of residual brick is formulated according to the different abrasions on both sides. Based on the changes of horizontal section, we use 3D software to draw a contour map of the residue brick (Figure 5). The contour map of the residue brick can show the ups and downs. It can display the change of $3 \mathrm{D}$ model in $2 \mathrm{D}$ plane. According to the contour map and the measurements, we found that part of the residual brick does not obey the geometry rules. The lines extended from the contour are not parallel (Figure 6). The reason may relate to the portrait brick's manufacture craft at that time and the degree of wear and tear. According to the existing model and the measured data, on the basis of keeping the image and structure, we use 3D software to repair residual brick model (Figure 7). The repaired model is a basic model, it cannot reflect the material of portrait brick. Its material and texture information need to be further complemented with the literature research.

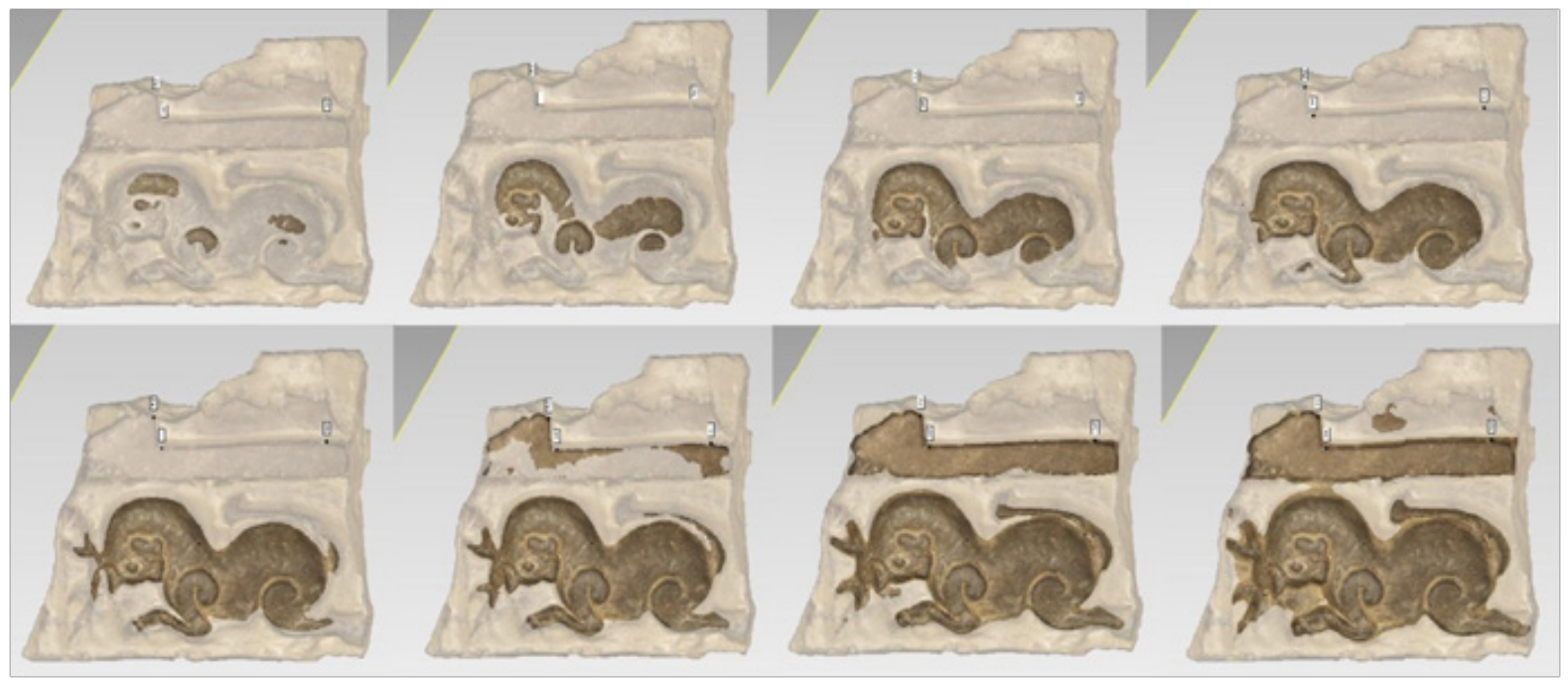

Figure 3 The changes of $A$ side.
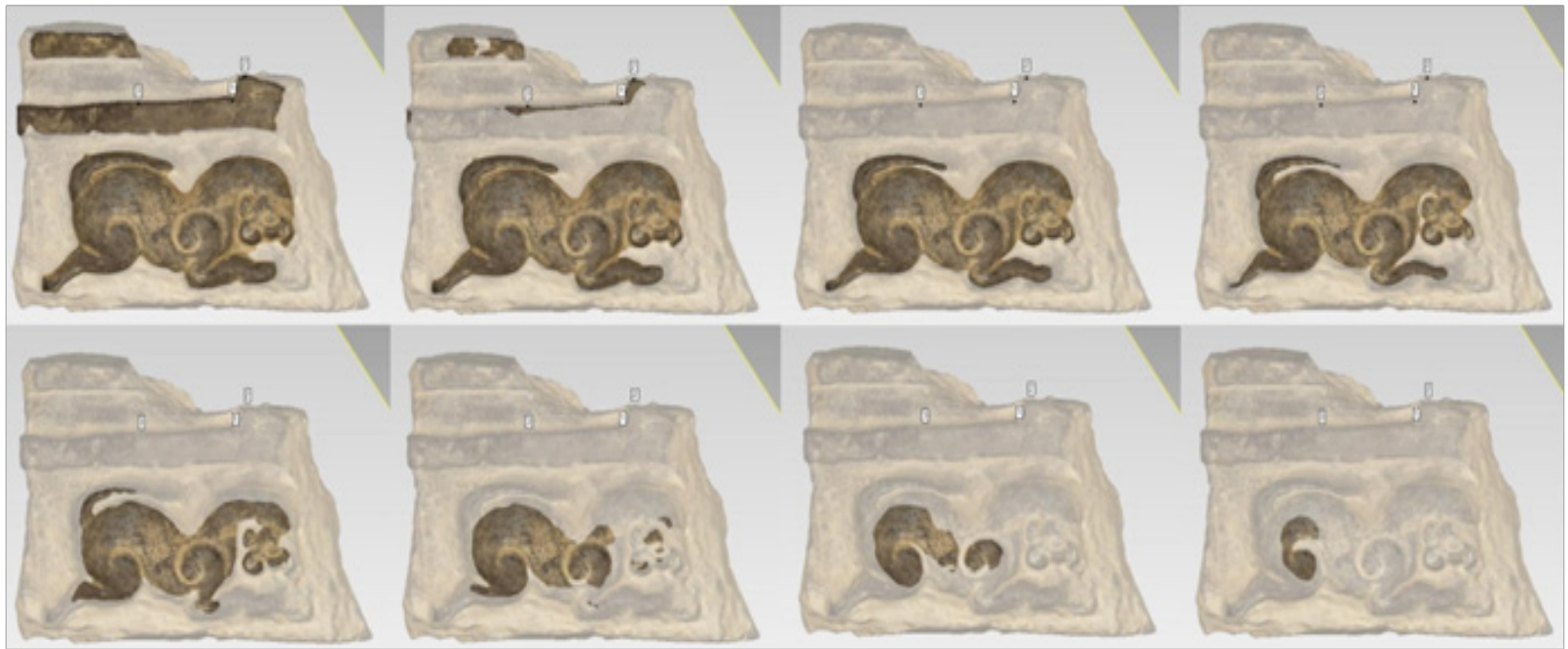

Figure 4 The changes of $B$ side. 


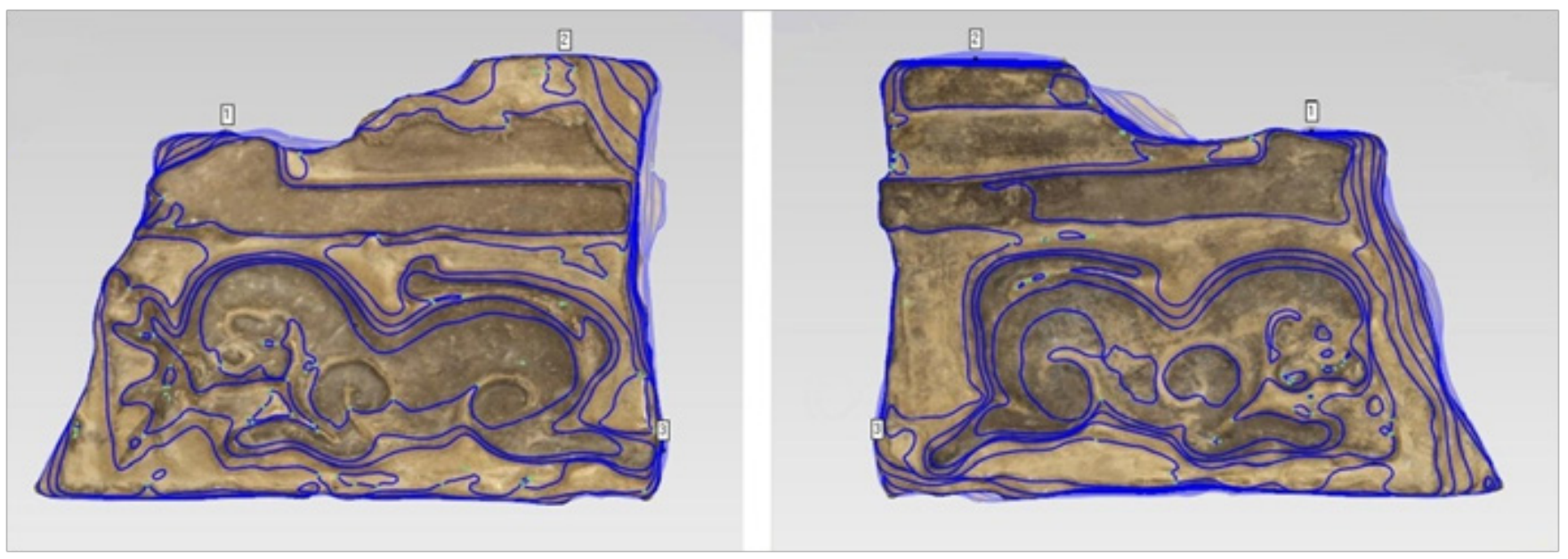

Figure 5 A contour map of the residue brick.

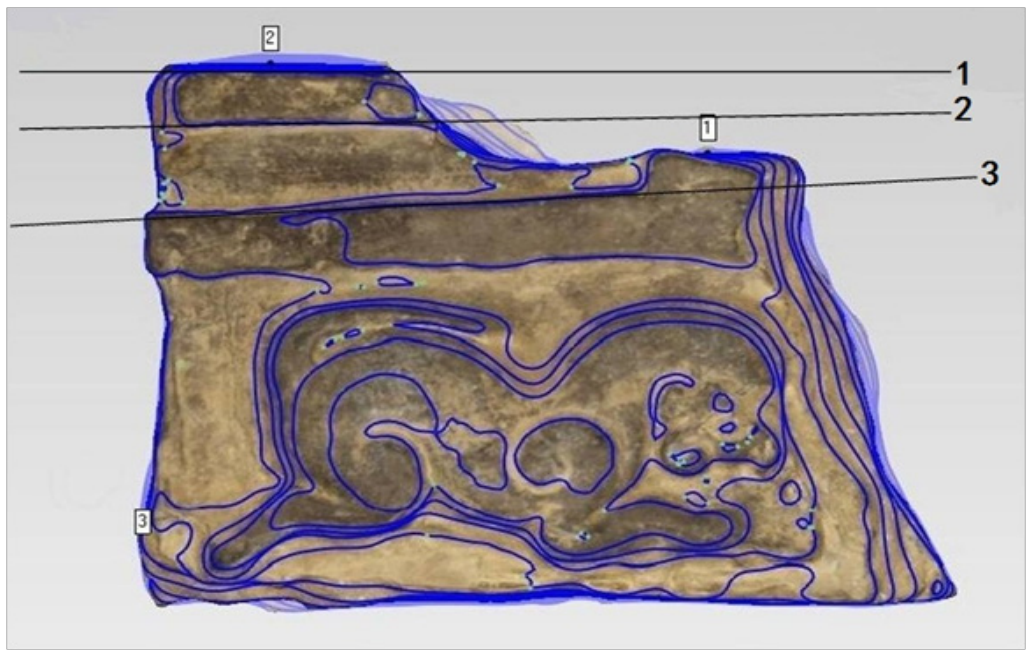

Figure 6 The lines extended from the contour are not parallel.
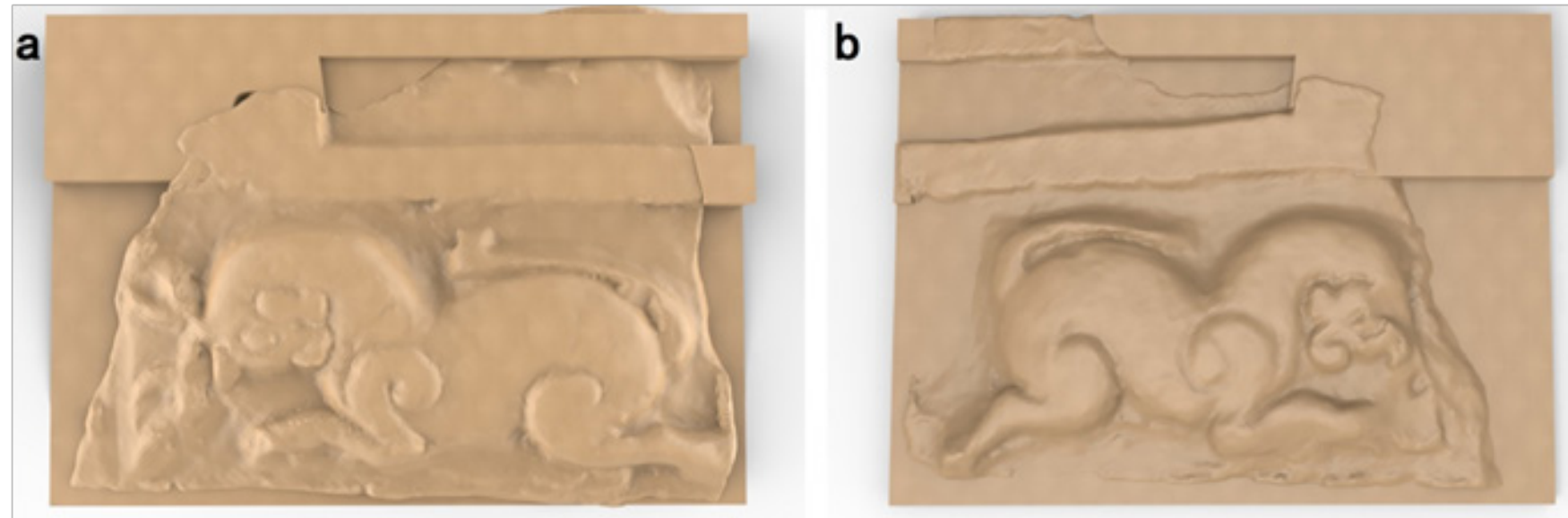

Figure 7 The repaired brick model. 


\section{Conclusion}

With the development of science and technology, 3D scanning technology has gradually become an important way of data collection for researching and protecting cultural relics. Compared with 3D laser scanning, white hand-held scanner is more suitable for smaller cultural relics. It can form a three-dimensional model directly and bring the texture information of cultural relics. Through data analysis and comparison of the model, we can determine the appearance change and wear degree, which provide reliable and accurate data information for the protection and repair of cultural relics. In the future work, we can make the virtual repair based on the 3D model and then use 3D printers to reproduce the re-engineering. With the development of surveying and mapping technology, white handheld scanner provides a faster and more accurate, non-contact solution. Based on the technological merit that is described above, this technology should be applied more broadly in the conservation of cultural heritage and archaeological work..$^{7-11}$

\section{Acknowledgments}

None.

\section{Funding}

My research project was fully sponsored by Shanxi University.

\section{Conflicts of interest}

Author declares that there is no conflict of interest.

\section{References}

1. China complete works of art, painting plait, stone brick. The Shanghai people's publishing house. 1988;3-6.

2. Wei wei. Review on the application of $3 \mathrm{D}$ laser scanning in conservation and archaeology. Sciences of conservation and archaeology. 2013;96107

3. Michael J, Georgios T, Andreas W. Laser scan measurement of the niche and virtual 3Drepresentation of the Buddha in Bamiyan. Proceedings of the 35th International Conference on Computer Applications and Quantitative Methods in Archaeology. 2007;83-90.

4. Diego Gonzalez Aguilera, Angel Munoz-Nieto, Pablo KodriguezGonzalvez Diego. New tools for rock art modelling: automated sensor integration in Pindal Cave. J Archaeol Sci. 2011;120-128.

5. Callieri M, Cignoni P, Dellepiane M. Pushing Time Of Flingt scanners to the limit. Proceeding of the 10th International Symposium on Virtual Realitc, Archaeology and Cultural. 2009;85-92.

6. Xu Shang. A study on hollow brick tombs in central China of the warring states, Qin and Han dynasties. Master's thesis, Nanjing university; 2019.

7. Sung ying-hsing. Exploitation of the Works of Nature, the Ming period. $1637 ; 75-82$.

8. The supplier of Creaform Go!SCAN 20 is AMETEK.

9. The supplier of Vxelements software 20 is AMETEK.

10. The supplier of $3 D$ builder is Microsoft Corporation.

11. The supplier of Geomagic Studio is Geomagic. 